\title{
Opis metodyki badania klinicznego pacjentów z zaburzeniami stawów skroniowo-żuchwowych według klasyfikacji DC/TMD
}

\author{
A description of the methodology for the clinical examination of patients \\ with temporomandibular disorders according to the standard Diagnostic Criteria \\ for Temporomandibular Disorders (DC/TMD)
}

\author{
${ }^{1}$ Katedra i Klinika Protetyki Stomatologicznej, Uniwersytet Medyczny im. Karola Marcinkowskiego w Poznaniu \\ ${ }^{2}$ Studenckie Koło Naukowe, Katedra i Klinika Protetyki Stomatologicznej \\ Uniwersytet Medyczny im. Karola Marcinkowskiego w Poznaniu
}

DOI: http://dx.doi.org/10.20883/df.2017.20

\begin{abstract}
Streszczenie
Nieprawidłowości w obrębie struktur układu stomatognatycznego związane są zwykle z dolegliwościami bólowymi i dyskomfortem dla pacjentów. Zaburzenia czynnościowe stawów skroniowo-żuchwowych mają negatywny wpływ na codzienne czynności, funkcjonowanie społeczne i jakość życia. W praktyce stomatologicznej konieczne jest szczegółowe poznanie symptomów towarzyszących owym dysfunkcjom. Jednym z głównych systemów klasyfikujących zaburzenia stawów skroniowo-żuchwowych były opublikowane w 1992 roku Badawcze Kryteria Diagnostyczne Zaburzeń Czynnościowych Układu Ruchowego Narządu Żucia (BKD/ZCURNŻ, Research Diagnostic Criteria for Temporomandibular Disorders, RDC/TMD). W 2013 roku pojawiła się nowa, udoskonalona klasyfikacja Diagnostic Criteria for Temporomandibular Disorders (DC/TMD), która stanowi następny krok w rozwoju diagnostyki zaburzeń stawów skroniowo-żuchwowych i wypiera starszą i mniej precyzyjną RDC/TMD. Celem publikacji było przedstawienie w postaci krótkiego opisu przebiegu badania klinicznego według protokołu DC/TMD oraz procedur zawartych w formularzu badania klinicznego. Protokół stworzony przez autorów klasyfikacji DC/TMD opisuje szereg czynności diagnostycznych przydatnych zarówno w badaniach przesiewowych, jak i w dokładnej ocenie danego przypadku klinicznego.
\end{abstract}

Słowa kluczowe: staw skroniowo-żuchwowy, dysfunkcje skroniowo-żuchwowe, RDC/TMD, DC/TMD.

\begin{abstract}
Abnormalities within the structures of the stomatognathic system are usually connected with pain and discomfort for the patients. Temporomandibular disorders (TMD) have a negative influence on daily activities and social functioning, as well as affecting the quality of life. Recognition of the symptoms accompanying these disorders is essential in dental practice, and finding efficient methods of diagnosis is important. One of the main TMD classification systems is the Research Diagnostic Criteria for Temporomandibular Disorders (RDC/TMD) published in 1992, which has been used extensively over the last two decades. In 2013 the new Diagnostic Criteria for Temporomandibular Disorders (DC/ TMD) were released and now they replace the old and less reliable RDC/TMD. The aim of this article is to present the information needed to perform clinical examinations according to standards of DC/TMD protocol and to give a concise specification of the procedures included in the DC/TMD examination form. The DC/TMD Protocol describes diagnostic activities useful not only in screening but also in precise evaluation of a given clinical case.
\end{abstract}

Keywords: temporomandibular joints, temporomandibular disorders, RDC/TMD, DC/TMD.

\section{Wstęp}

Zaburzenia czynnościowe stawów skroniowo-żuchwowych (SSŻ) mogą dotyczyć nawet ponad $10 \%$ populacji [1] i są drugą co do częstości występowania nieprawidłowością układu mięśniowo-szkieletowego, przyczyniającą się do przewlekłego bólu oraz niepełnosprawności [2]. Zagadnienie to $\mathrm{w}$ ciągu ostatnich dziesięcioleci coraz bardziej przyciąga uwagę zarówno klinicystów, jak i badaczy.

W 1992 roku została opublikowana klasyfikacja Research Diagnostic Criteria for Temporomandi- bular Disorders (RDC-TMD), która miała na celu usystematyzowanie najbardziej powszechnych zaburzeń SSŻ i była oparta na modelu biopsychosocjalnym. Składała się z dwóch osi (Axis I oraz Axis II), z których pierwsza badała stan kliniczny pacjenta, natomiast druga oceniała psychologiczny wymiar bólu, intensywność, niepełnosprawność wynikającą z bólu oraz obecność depresji i niespecyficznych objawów, w opraciu o samodzielną opinię pacjenta [3]. Badawcze kryteria diagnostyczne RDC/TMD zostały oficjalnie przetłumaczone na kilkanaście języków (w tym język polski) i zostały za- 
akceptowane przez międzynarodowe konsorcjum zajmujące się określeniem standardów diagnostyki i leczenia [4]. Tłumaczenie było przeprowadzone formalnie (tj. przy użyciu tak zwanych procedur tłumaczenia i tłumaczenia zwrotnego), ponieważ przetłumaczona wersja powinna mierzyć te same wartości, co oryginalna wersja napisana w języku angielskim [5]. Mimo uznania klasyfikacji RDC/ TMD za system modelowy oraz jej rozległego użytkowania w przeciągu ostatnich 20 lat, autorzy już na początku uznali konieczność dalszych badań w celu poprawy dokładności diagnozy. Przeprowadzona dyskusja podczas wielu sympozjów i warsztatów doprowadziła w 2013 roku do zredagowania nowej, udoskonalonej klasyfikacji, Diagnostic Criteria for Temporomandibular Disorders (DC/TMD) [2]. Klasyfikacja DC/TMD jest obecnie w trakcie oficjalnego tłumaczenia na język polski, natomiast niniejsza publikacja stworzona została z zamiarem przekazania informacji niezbędnych do przeprowadzenia badania klinicznego wedle standardów ustalonych przez jej autorów.

\section{Cel pracy}

Celem publikacji jest krótki opis przebiegu badania klinicznego według protokołu DC/TMD oraz procedur zawartych $\mathrm{w}$ formularzu badania klinicznego.

\section{Opis klasyfikacji DC/TMD}

Klasyfikacja DC/TMD, podobnie do wcześniej utworzonej RDC/TMD, również zakłada dwuosiowe podejście do diagnostyki zaburzeń SSŻ [6]. $\mathrm{Na}$ oś pierwszą (Axis I) składa się formularz badania klinicznego oraz szereg ankiet badających somatyczny wymiar bólu. Należą do nich: kwestionariusz przesiewowy dotyczący występowania bólu w obrębie twarzy (Tmd-pain screener), ankieta demograficzna (Demographics) odnosząca się do stanu cywilnego, etniczności, edukacji oraz poziomu zarobków pacjenta, a także kwestionariusz analizujący występowanie objawów zaburzeń SSŻ (Symptom Questionnaire) tj. bólu w obrębie twarzy, bólu głowy, efektów akustyczne w stawach oraz blokowania żuchwy. Natomiast oś druga (Axis II) pozwala ocenić wpływ bólu na sferę psychologiczną pacjenta, niepełnosprawność wywołaną dolegliwościami bólowymi, a także obecność depresji i innych niespecyficznych objawów. W skład tej osi wchodzi ankieta, w której pacjent zaznacza na odpowiednich diagramach miejsca występowania bólu na ciele (Pain Drawing), stopniowa skala bólu chronicznego (Graded Chronic Pain Scale). Ankieta zawiera także skale ograniczenia funkcjonalnego otwarcia żuchwy (JFLS-8, JFLS-20), kwestionariusze badające obecność depresji lub ogólnych zaburzeń lękowych u pacjenta (PHQ-4, PHQ-9, PHQ-15, GAD-7) oraz listę parafunkcji dotyczących jamy ustnej (Oral Behaviors Checklist) [7]. Schemat postępowania oraz ogólne zasady badania klasyfikacji DC/TMD są zawarte w protokole DC/TMD [8]. Przestrzeganie określonych wytycznych konieczne jest do prawidłowego przeprowadzenia badania oraz dokładnej diagnozy. W celu ujednolicenia danych przedstawiających częstość występowania oraz nasilenie dolegliwości bólowych dla większości pozycji obecnych w ankietach osi pierwszej został przyjęty okres ostatnich $30 \mathrm{dni}[8]$.

\section{Opis badania klinicznego według Protoko- tu DC/TMD Axis I}

Wszystkie procedury wykonywane $w$ trakcie badania odnoszą się do sytuacji, gdy pacjent siedzi wyprostowany na krześle o regulowanej wysokości, natomiast lekarz stoi po jego prawej stronie. $\mathrm{Pa}$ cjent posiadający ruchomą protezę powinien mieć ją założoną na czas badania, o ile jest ona stabilna lub istnieje możliwość jej stabilizacji na czas pomiarów wykorzystujących zęby jako punkty orientacyjne, w przeciwnym wypadku proteza powinna zostać wyjęta z jamy ustnej przed badaniem. Dotyczy to również wszystkich ruchomych aparatów, które nie mają na celu zastąpienia naturalnych zębów. Do przeprowadzenia niezbędnych pomiarów potrzebna jest linijka, której koniec równy jest z wartością „0”, ponieważ wtedy nie stanowi ona przeszkody dla wargi górnej pacjenta, gdy jego zęby górne wykorzystywane są jako punkty orientacyjne. Wszystkie wyniki zaokrąglane są w dół i podawane jako dwucyfrowe liczby całkowite, na przykład liczba $41,7 \mathrm{~mm}$ zostaje przekształcona do $41 \mathrm{~mm}$. Dla wartości mniejszych od 10 dana cyfra poprzedzana jest przez „0", np. dla nagryzu pionowego (overbite) równego $2 \mathrm{~mm}$ w formularzu podaje się wynik „02”. Badanie kliniczne w postaci palpacji to procedura mająca na celu wywołanie bólu podobnego do tego, który pacjent odczuwa na co dzień, poprzez stosowanie nacisku o sile $0,5 \mathrm{~kg}$ lub $1 \mathrm{~kg}$ w zależności od badanej struktury. Konieczne jest skalibrowanie siły nacisku przy pomocy algometru. Palpacja składa się z następujących po sobie faz: początkowy kontakt ze skórą, zwiększenie nacisku do pożądanej wartości, utrzymywanie odpowiedniej siły nacisku przez określony czas. Cały cykl trwa około 2 sekundy, z których jedna sekunda to czas trwania stałego nacisku. W celu standaryzacji badania rekomendowane jest używanie jednego palca do palpacji. Jeżeli w trakcie badania wystąpią u pacjenta dolegliwości bólowe, zadaniem lekarza jest zapytanie, czy są one znajome (tj. wystąpiły w ciągu ostatnich 
30 dni) oraz czy są skojarzone np. z jakąś czynnością. Jeśli obszar występowania bólu wychodzi poza granice mięśnia lub stawu poddanego palpacji, jest zdefiniowany jako ból przeniesiony.

Kolejność wykonywanych procedur określona jest przez formularz badania klinicznego (DC/ TMD Examination Form), w którym rejestrowane są również wszystkie wyniki otrzymane podczas oględzin. Ankieta składa się z dwunastu punktów, z których pierwszych dziesięć stanowi właściwą część badania, a dwa ostatnie to diagnoza oraz komentarz lekarza.

Punkt pierwszy (Location of Pain: last 30 days) zawarty $\mathrm{w}$ formularzu skupia się na przybliżeniu badającemu historii bólowej pacjenta $z$ ostatnich 30 dni, dotyczącej układu stomatognatycznego oraz bólu głowy. Lekarz zaczyna od obustronnego badania lekkim dotykiem okolicy skroniowej, żwaczowej, tylno-żuchwowej, podżuchwowej oraz stawów skroniowo-żuchwowych bez podawania ich nazw pacjentowi. Następnie instruuje badanego, by wskazał palcem te z wyżej wymienionych miejsc, w których wystąpiły dolegliwości bólowe w ciągu ostatnich 30 dni. Lekarz ponownie identyfikuje obszary wyznaczone przez pacjenta, aby wykluczyć objawy pochodzące ze struktur nieistotnych dla badania. Dla bólu głowy sytuacja jest bardzo podobna, bowiem badający ponownie daje polecenie pacjentowi, aby pokazał palcem miejsca, w których wystąpił ból w okresie ostatnich 30 dni. Następnie, w celu potwierdzenia, sam bada wskazane obszary i rejestruje wyniki w formularzu. Jeżeli podczas procedur mających na celu wywołanie bólu pojawi się on w niezaznaczonym dotychczas miejscu, zostaje ono uzupełnione w formularzu.

W punkcie drugim (Incisal Relationships) należy podać wartości nagryzu poziomego (overjet), pionowego (overbite) oraz rozbieżności pomiędzy liniami pośrodkowymi szczęki i żuchwy. Dla wykonanych pomiarów należy zaznaczyć użyty punkt referencyjny. W większości przypadków będzie to prawy bądź lewy centralny siekacz szczęki. Działania te pozwolą na dokładne odzwierciedlenie zakresu ruchomości żuchwy.

Punkt trzeci (Opening Pattern) został zakwalifikowany jako procedura uzupełniająca i nie należy do zestawu głównych elementów badania. Znajduje ona zastosowanie $w$ diagnozie przemieszczenia krążka stawowego, przykurczy lub jednostronnego bólu mięśni żwaczy. Procedura ma na celu stwierdzenie, czy podczas otwierania ust występuje zbaczanie żuchwy, występujące z powrotem lub bez powrotu do linii środkowej.

Punkt czwarty (Opening Movements) ocenia zakres samodzielnego maksymalnego otwarcia ust, pierwszy pomiar bez występowania dolegliwości bólowych. Zmierzona zostaje odległość między brzegiem siecznym zęba referencyjnego, wybranego w punkcie drugim, a brzegiem siecznym zęba przeciwstawnego w żuchwie. Kolejny pomiar dotyczy maksymalnego samodzielnego otwarcia ust, po którym pacjent pokazuje lekarzowi miejsca ewentualnego pojawienia się bólu. Trzeci wynik uzyskiwany jest przez zmierzenie maksymalnego otwarcia ust dokonanego wraz z asystą lekarza. Musi być on co najmniej tej samej wartości, co poprzedni. Ostatnim punktem tej procedury jest zaznaczenie, czy otwarcie ust nastąpiło w maksymalnym zakresie czy też zostało przedwcześnie zakończone przez pacjenta.

Punkt piąty (Lateral and Protrusive Movements) pozwala ocenić zakres ruchu doprzedniego i ruchów bocznych. Jest to procedura uzupełniająca, istnieje więc możliwość pominięcia tego badania. Po wykonaniu każdego z trzech pomiarów pacjent powinien pokazać palcem miejsca, w których wystąpił ból podczas wykonywania danego ruchu.

Punkt szósty (TMJ Noises During Open \& Close Movements) służy wykryciu objawów akustycznych, charakterystycznych dla zaburzeń SSŻ. Lekarz lokalizuje okolicę SSŻ i kładzie na niej palec. Pacjent zostaje poinstruowany, aby trzykrotnie z pozycji maksymalnego zaguzkowania otworzył usta i następnie je zamknął. Podczas tej procedury zarówno lekarz, jak i pacjent starają się ocenić występowanie objawów akustycznych w trakcie ruchów żuchwy. Dodatkowo należy ustalić, czy wystąpieniu takich objawów towarzyszyły dolegliwości bólowe.

Punkt siódmy (TMJ Noises During Lateral \& Protrusive Movements) jest uzupełnieniem poprzedniego pytania i bada te same efekty akustyczne przy trzykrotnym wykonywaniu ruchów laterotruzyjnych i ruchu protruzyjnego.

Punkt ósmy (Joint Locking) określa, czy u pacjenta występuje zablokowanie SSŻ. Pod uwagę brane są dwie sytuacje, mianowicie ruch otwierania ust oraz moment, w którym usta są szeroko otwarte. Istotne dla tej procedury jest to, czy pacjent umie samodzielnie odblokować staw czy wymagana jest do tego asysta lekarza.

Punkt dziewiąty (Muscle and TMJ Pain with Palpation) skupia się na palpacji mięśni żucia oraz okolicy SSŻ w celu wywołania u pacjenta bólu podobnego do tego, który odczuwa na co dzień. Lekarz przy pomocy opuszki jednego palca najpierw lokalizuje daną okolicę po jednej stronie twarzy pacjenta, podczas gdy drugą ręką asekuruje głowę bądź żuchwę badanego po przeciwnej stronie. Po odnalezieniu docelowej struktury lekarz wywiera na nią skalibrowany algometrem nacisk o sile $1 \mathrm{~kg}$ 
dla mięśni i 0,5 kg dla stawów. Nacisk ma trwać przez 2 sekundy lub 5 sekund, gdy przedmiotem badania jest ból przeniesiony (referred pain), odczuwany poza granicami badanej struktury. Ważnym aspektem tej procedury jest każdorazowe zapytanie po palpacji danej okolicy, czy pacjent odczuł w tym momencie badania ból oraz czy jest to znajoma dolegliwość.

Punkt dziesiąty (Supplemental Muscle Pain with Palpation) jest fakultatywnym uzupełnieniem poprzedniego i dotyczy pozostałych mięśni żucia.

Punkt jedenasty obejmuje diagnozę, na którą składają się dolegliwości bólowe: ból mięśniowy (myalgia), ból powięziowy przeniesiony (myofascial pain with referral), ból stawowy (arthralgia) i ból głowy związany z zaburzeniami SSŻ (headache attributed to TMD). Diagnoza obejmuje także zaburzenia prawego i lewego SSŻ: przemieszczenie krążka stawowego bez lub z zablokowaniem oraz ewentualnym ograniczeniem otwierania ust, a także zmiany zwyrodnieniowe SSŻ i dyslokację krążka stawowego.

Punkt dwunasty stanowi miejsce na komentarz do badania, gdzie lekarz może zapisać dodatkowe obserwacje i uwagi odnośnie do danego przypadku klinicznego [8].

\section{Podsumowanie}

Potrzeba wczesnej i szybkiej diagnostyki dysfunkcji skroniowo-żuchwowych zaowocowała wieloma schematami badań. Obiektywne oznaki zaburzeń SSŻ mogą być ocenione w trakcie przeprowadzania wywiadu oraz badania klinicznego. Obecnie najbardziej zalecaną klasyfikacją diagnostyczną jest Diagnostic Criteria for Temporomandibular Disorders (DC/TMD) jako kontynuacja oraz udoskonalenie Research Diagnostic Criteria for Temporomandibular Disorders (RDC/TMD). Głównymi cechami klasyfikacji DC/TMD, dającymi jej przewagę nad RDC/TMD, są: większa wiarygodność, szersza diagnostyka oraz uproszczenie procedur badania klinicznego [2]. Wszystkie procedury zawarte w badaniu wg klasyfikacji DC/TMD zostały ściśle opisane w protokole, aby zapewnić ich powtarzalność oraz dokładność w warunkach klinicznych. Do postawienia właściwej diagnozy nie jest konieczne wykonanie wszystkich procedur formularza klinicznego, jednak dodatkowe badania pozwalają lekarzowi na szersze poznanie dolegliwości pacjenta.

\section{Oświadczenia}

Oświadczenie dotyczące konfliktu interesów

Autorzy deklarują brak konfliktu interesów w autorstwie oraz publikacji pracy.

\section{Źródła finansowania}

Autorzy deklarują brak źródeł finansowania.

\section{Piśmiennictwo}

[1] Vilanova LS, Garcia RC, List T, Alstergren P. Diagnostic criteria for temporomandibular disorders: self-instruction or formal training and calibration? The Journal of Headache and Pain. 2015;16:26.

[2] Schiffman E, Ohrbach R, Truelove E, et al. Diagnostic Criteria for Temporomandibular Disorders (DC/TMD) for Clinical and Research Applications: Recommendations of the International RDC/TMD Consortium Network and Orofacial Pain Special Interest Group. J Oral Facial Pain Headache, 2014;28(1):6-27.

[3] Dworkin SF, LeResche L. Research diagnostic criteria for temporomandibular disorders: review, criteria, examinations and specifications, critique. J Craniomandib Disord. 1992;6:301-355.

[4] International Consortium for RDC/TMD- based Research. Available at: www.rdc-tmdinternational.org.

[5] Osiewicz MA, Lobbezoo F, Loster BW, Wilkosz M, Naeije $M$, Ohrbach R. Badawcze kryteria diagnostyczne zaburzeń czynnościowych układu ruchowego narządu żucia BKD/ZCURNŻ - polska wersja dwuosiowego systemu diagnostycznego ZCURNŻ. Protet Stomatol. 2010;6(LX): 433-444.

[6] Sójka A, Abu-Fillat Y, Hędzelek W. Research diagnostic criteria for temporomandibular disorders (RDC/TMD) as the first step to introduce reliable and valid diagnostic criteria for tmd. Issue Rehabil. Orthop. Neurophysiol. Sport Promot. 2016;17:105-113.

[7] Ohrbach R, editor. Diagnostic Criteria for Temporomandibular Disorders: Assessment Instruments. Version 15 May 2016. www.rdc-tmdinternational.org Dostęp dnia 8.10.2016.

[8] Ohrbach R, Gonzalez Y, List T, Michelotti A, Schiffman E, Diagnostic Criteria for Temporomandibular Disorders (DC/ TMD) Clinical Examination Protocol: Version 2 June 2013 www.rdc-tmdinternational.org Dostęp dnia 8.10.2016.

Zaakceptowano do edycji: 2017-09-01 Zaakceptowano do publikacji: 2017-11-02

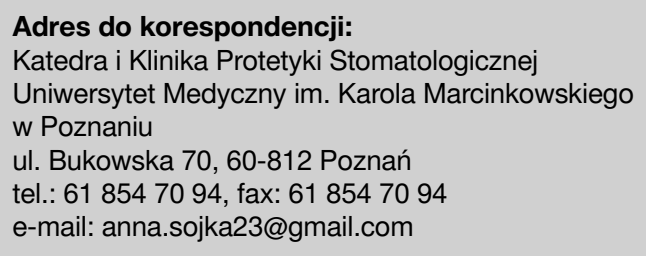

